Ethnopharmacological communication

\title{
Acute and subacute toxicity of Salvia scutellarioides in mice and rats
}

\author{
Jorge H. Ramírez ${ }^{\mathrm{a}, *}$, Mauricio Palacios ${ }^{\mathrm{a}}$, Oscar Tamayo ${ }^{\mathrm{b}, 1}$, \\ Roberto Jaramillo ${ }^{\mathrm{c}}$, Oscar Gutiérrez ${ }^{\mathrm{a}}$ \\ a Facultad de Salud, Sección de Farmacología, Universidad del Valle, Cali, Colombia \\ ${ }^{\mathrm{b}}$ Facultad de Salud, Programa de Medicina, Universidad Santiago de Cali, Cali, Colombia \\ ${ }^{\mathrm{c}}$ Centro Internacional de Entrenamiento e Investigación Medica (CIDEIM), Cali, Colombia
}

Received 29 March 2006; received in revised form 11 July 2006; accepted 31 July 2006

Available online 12 August 2006

\begin{abstract}
The acute and subacute toxicity of the aqueous extract of Salvia scutellarioides (Lamiaceae) was studied in mice and rats. In the acute toxicity test, oral administration of $2 \mathrm{~g} / \mathrm{kg}$ of Salvia scutellarioides produced neither mortality nor changes in behavior or any other physiological activities. In subacute toxicity studies, no mortality was observed when the two doses of 1 or $2 \mathrm{~g} / \mathrm{kg}$ day of aqueous extract of Salvia scutellarioides extract were administered orally for a period of 28 days. In the blood chemistry analysis, no significant changes occurred, including glucose, creatinine, blood urea nitrogen (BUN), aspartate transaminase (AST), alanine transaminase (ALT), potassium, sodium, chloride, calcium, phosphorus, conjugated billirrubin, total billirrubin, total cholesterol, high density lipoprotein (HDL), triglycerides, total protein, albumin, prothrombin time (PT) and thromboplastin partial time (PTT) of both sexes. Hematological analysis showed no differences in any of the parameters examined (WBC count, platelet and hemoglobin estimation) in either the control or treated group of both sexes. The urinalysis was negative for glucose, ketonic bodies, casts, red blood cells, and albumin in the control and treatment groups. There were no significant differences in the body and organ weights between controls and treated animals of both sexes. Pathologically, neither gross abnormalities nor histopathological changes were observed.
\end{abstract}

(C) 2006 Elsevier Ireland Ltd. All rights reserved.

Keywords: Lamiaceae; Salvia scutellarioides; Folklore medicine; Subacute toxicity; Herbal medicine

\section{Introduction}

Salvia scutellarioides Kunth Syn. Salvia palaefolia (Lamiaceae) is an abundant aromatic plant endemic in the pacific and central regions of Colombia, where it is commonly known as "mastranto". Infusions of the bark and leaves from Salvia scutellarioides are commonly used in folk medicine for their antihypertensive and diuretic properties (Piñeros et al., 1991; Garcia, 1992; Colmenares and Ramírez, 2001). Recently, our research group reported the effects of Salvia scutellarioides in lowering the blood pressure in L-NAME hypertensive rats (Ramirez et al., 2006b) and also their diuretic effect in normal rats (Ramirez et al., 2006a). Alkaloids, triterpenes and lignans were previously reported as chemical constituents from this plant (Gonzalez et al., 1990). Despite the wide use of Salvia scutellarioides in

\footnotetext{
* Corresponding author. Tel.: +57 25185620.

E-mail address: jorgehramirez31@yahoo.com (J.H. Ramírez).

1 Present address: Universidad Santiago de Cali, Sede San Fernando, Calle 4B 36-00, Edificio 116, Cuarto piso, Oficina 4035, Cali, Colombia.
}

Colombian folk medicine, no study has been published in the scientific literature about its toxicological profile.

The present study was designed to determine the acute and subacute oral toxicity of the aqueous extract from bark and leaves of Salvia scutellarioides in Wistar rats. In addition, the effects of the administration of the plant in blood pressure of normotensive animals was also evaluated.

\section{Materials and methods}

\subsection{Plant material}

Salvia scutellarioides was acquired from a local herbal store in March 2003. Its identity was confirmed by Dr. Phillipe Silverstone (Department of Botanical Biology, Universidad del Valle) and a voucher specimen (JHR-01) was deposited at the Herbarium of the Natural Sciences Institute of the Universidad del Valle, Colombia. The bark and leaves of Salvia scutellarioides were dried at $38^{\circ} \mathrm{C}$ for $72 \mathrm{~h}$, followed by mechanical fragmentation for posterior storage in sealed container bags at $0^{\circ} \mathrm{C}$. 


\subsection{Preparation of the extract}

Infusions of the dried powdered bark and leaves of the plant $(20 \mathrm{~g})$ were extracted with distilled water $(500 \mathrm{ml})$, followed by filtration and concentration (yield: $40 \%$ ) with vacuum.

\subsection{Acute toxicity}

The acute toxicity of the extract of Salvia scutellarioides was evaluated in mice using the up and down procedure (OECD, 2001b).

Mice of either sex (three females and three males, weight: 25-35 g, age: 6-8 weeks) received Salvia scutellarioides aqueous extract starting at $2 \mathrm{~g} / \mathrm{kg}$ orally by gavage. The animals were observed for toxic symptoms continuously for the first $4 \mathrm{~h}$ after dosing. Finally, the number of survivors was noted after $24 \mathrm{~h}$ and these animals were then maintained for further 13 days with observations made daily.

\subsection{Subacute toxicity}

\subsubsection{Experimental animals}

Thirty Wistar rats (weight: $150-250 \mathrm{~g}$; age: 6-8 weeks old) were randomly assigned into three groups $(n=10)$, five females and five males in each group. Groups of five rats were housed together in stainless steal cages (males separated from females) with $12 \mathrm{~h}$ light/dark cycle in a temperature and humidity controlled environment. Treatments were administered orally by gavage once a day for 4 weeks. The first group of animals, serving as control, received normal saline $(5 \mathrm{ml} / \mathrm{kg})$; the second and third group received the water extract of Salvia scutellarioides at doses of 1 and $2 \mathrm{~g} / \mathrm{kg}$, respectively. All animals were supplied with Fiel Purina Chow ${ }^{\circledR}$ and tap water ad libitum during the testing periods.

All rats were weighted and observed daily for physiological and behavioral changes. Any rat that died during the test period was tested pathologically, and all animals were examined at the end of the test period.

\subsubsection{Observation and examination methods}

Clinical signs were observed at least once a day through the 28 days of dosing. Body weight, water and food intake and weight gain were measured once a week. Systolic blood pressure (SBP) and mean blood pressure (MBP) were measured weekly in conscious, prewarmed, restrained rats by tail-cuff plethysmography using a piezoelectric transducer (Model 631 Six Channel Semiautomatic NIBP Test System. IITC, Inc., Los Angeles, CA). Diastolic blood pressure (DBP) was extrapolated from the SBP and MBP using the following formula:

$\mathrm{DBP}=\frac{3 \mathrm{MBP}-\mathrm{SBP}}{2}$

\subsubsection{Urine samples}

On day 27 th, the rats were placed in metabolic cages during 4-6 h; 3-5 $\mathrm{ml}$ of urine were collected for immediate urinalysis.

\subsubsection{Blood analysis}

On day 29th all surviving animals were fasted overnight, and anesthetized afterwards for blood collection from the right ventricle. Blood samples were collected into three tubes: (1) $3.2 \%$ buffered sodium citrate tubes; (2) heparinized centrifuge tubes; (3) dry non-heparinized centrifuge tubes. A blood analysis (hematology, coagulation and chemistry) was carried out. The blood in the sodium citrate tubes was used for prothrombin time (PT) and partial thromboplastin time (PTT) estimation. The heparinized blood was used for a hematological study which included red blood cell count (RBC), hemoglobin concentration $(\mathrm{Hb})$, hematocrit $(\mathrm{Ht})$, mean corpuscular volume (MCV), mean corpuscular hemoglobin (MCH), mean corpuscular hemoglobin concentration (MCHC), platelets (Plt),

Table 1

Systolic and diastolic blood pressures of rats in subacute toxicity of the aqueous extract from Salvia scutellarioides

\begin{tabular}{|c|c|c|c|c|c|c|}
\hline \multirow[t]{3}{*}{ Week } & \multicolumn{2}{|l|}{ Control } & \multicolumn{4}{|c|}{ Salvia scutellarioides (g/kg) } \\
\hline & \multirow[t]{2}{*}{ SBP } & \multirow[t]{2}{*}{ DBP } & \multicolumn{2}{|l|}{1} & \multicolumn{2}{|l|}{2} \\
\hline & & & SBP & $\mathrm{DBP}$ & SBP & $\mathrm{DBP}$ \\
\hline \multicolumn{7}{|l|}{ Male } \\
\hline 0 & $119.4 \pm 3.8$ & $83.4 \pm 3.90$ & $116.2 \pm 2.33$ & $86.8 \pm 2.66$ & $122 \pm 4.74$ & $92.9 \pm 2.14$ \\
\hline 1 & $131.6 \pm 7.25$ & $84.8 \pm 3.75$ & $121 \pm 9.82$ & $79.3 \pm 7.33$ & $124.6 \pm 3.26$ & $92.8 \pm 2.38$ \\
\hline 2 & $138.8 \pm 5.51$ & $104.9 \pm 4.22$ & $149.8 \pm 10.1$ & $97 \pm 8$ & $126.8 \pm 5.2$ & $94 \pm 1.51$ \\
\hline 3 & $127.6 \pm 8.27$ & $93.7 \pm 6.79$ & $130.1 \pm 2.91$ & $94.4 \pm 4.74$ & $128.4 \pm 5.07$ & $90.3 \pm 6.62$ \\
\hline 4 & $143 \pm 1.61$ & $102.8 \pm 2.46$ & $138.2 \pm 3.65$ & $107.9 \pm 5.65$ & $136.8 \pm 7.17$ & $99 \pm 7.95$ \\
\hline \multicolumn{7}{|c|}{ Female } \\
\hline 0 & $126.4 \pm 2.94$ & $93.4 \pm 3.82$ & $118.6 \pm 1.99$ & $87.7 \pm 3.72$ & $114.2 \pm 5.52$ & $83.3 \pm 6.58$ \\
\hline 1 & $114 \pm 4.47$ & $82.8 \pm 2.08$ & $124.6 \pm 4.64$ & $85 \pm 2.2$ & $118.6 \pm 4.38$ & $83.2 \pm 5$ \\
\hline 2 & $115.6 \pm 4.15$ & $88.6 \pm 2.89$ & $122.4 \pm 7.8$ & $83.4 \pm 10.1$ & $108 \pm 5.33$ & $74.7 \pm 3.72$ \\
\hline 3 & $111 \pm 7.32$ & $82.2 \pm 2.37$ & $116.6 \pm 6$ & $77.3 \pm 7.02$ & $112.2 \pm 7.17$ & $78.3 \pm 7.28$ \\
\hline 4 & $107.4 \pm 5.81$ & $74.4 \pm 8.44$ & $105.4 \pm 4.57$ & $74.5 \pm 4.21$ & $108.2 \pm 3.64$ & $81.5 \pm 2.81$ \\
\hline
\end{tabular}

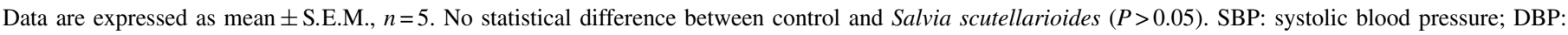
diastolic blood pressure. 
Table 2

Hematological values of rats in subacute toxicity of the aqueous extract from Salvia scutellarioides

\begin{tabular}{|c|c|c|c|c|c|c|}
\hline & \multicolumn{3}{|l|}{ Male } & \multicolumn{3}{|l|}{ Female } \\
\hline & \multirow[t]{2}{*}{ Control } & \multicolumn{2}{|c|}{ Salvia scutellarioides $(\mathrm{g} / \mathrm{kg})$} & \multirow[t]{2}{*}{ Control } & \multicolumn{2}{|c|}{ Salvia scutellarioides $(\mathrm{g} / \mathrm{kg})$} \\
\hline & & 1 & 2 & & 1 & 2 \\
\hline $\mathrm{RBC}^{\mathrm{a}}$ & $8.8 \pm 0.36$ & $9.27 \pm 0.41$ & $9.95 \pm 1.02$ & $8.83 \pm 0.62$ & $9.16 \pm 0.46$ & $7.9 \pm 0.7$ \\
\hline $\mathrm{Hb}^{\mathrm{b}}$ & $15.04 \pm 1.04$ & $17.48 \pm 0.94$ & $17.7 \pm 0.58$ & $15 \pm 0.4$ & $15.1 \pm 0.47$ & $15.6 \pm 0.29$ \\
\hline $\mathrm{Ht}^{\mathrm{c}}$ & $48.46 \pm 2.46$ & $53.68 \pm 1.75$ & $56.58 \pm 3.45$ & $48.5 \pm 1.71$ & $49.75 \pm 1.97$ & $48.73 \pm 1.38$ \\
\hline $\mathrm{MCV}^{\mathrm{d}}$ & $55.2 \pm 1.24$ & $58 \pm 2.27$ & $55 \pm 1.23$ & $55.6 \pm 2.66$ & $54.5 \pm 0.87$ & $62.5 \pm 3.38$ \\
\hline $\mathrm{WBC}^{\mathrm{g}}$ & $6.25 \pm 1.55$ & $7.5 \pm 2.32$ & $6.5 \pm 0.99$ & $5.72 \pm 1.96$ & $3.98 \pm 0.54$ & $7.46 \pm 2.57$ \\
\hline Seg. ${ }^{\text {h }}$ & $15.2 \pm 5.49$ & $18.25 \pm 3.66$ & $20.5 \pm 5.5$ & $13.8 \pm 0.73$ & $12 \pm 0.82$ & $12 \pm 2.83$ \\
\hline Lymp. ${ }^{\mathrm{i}}$ & $79.8 \pm 5.55$ & $76.75 \pm 3.52$ & $76.75 \pm 5.74$ & $82.6 \pm 1.75$ & $86 \pm 1.08$ & $83 \pm 2.68$ \\
\hline Mono. ${ }^{\mathrm{j}}$ & $4 \pm 1.38$ & $3.25 \pm 1.32$ & $2 \pm 0.71$ & $2.4 \pm 1.17$ & $1.25 \pm 0.25$ & $3.25 \pm 1.03$ \\
\hline Eosi. ${ }^{k}$ & $0.8 \pm 0.37$ & $1.75 \pm 1.03$ & $0.25 \pm 0.25$ & $0.6 \pm 0.4$ & $1 \pm 0.41$ & $2 \pm 0.71$ \\
\hline PLT. ${ }^{l}$ & $906.2 \pm 101$ & $924.3 \pm 105.8$ & $1087 \pm 27.38$ & $913.8 \pm 96.3$ & $1242 \pm 63.75$ & $1007 \pm 93.4$ \\
\hline
\end{tabular}

Data are expressed as mean \pm S.E.M., $n=5$. No statistical difference between control and Salvia scutellarioides $(P>0.05)$.

${ }^{\text {a }}$ Red blood cell $\left(\times 10^{6} \mathrm{~mm}^{-3}\right)$.

${ }^{\mathrm{b}}$ Hemoglobin concentration $(\mathrm{g} / \mathrm{dl})$.

c Hematocrit (\%).

d Mean corpuscular volume (FL).

${ }^{\mathrm{e}}$ Mean corpuscular hemoglobin (pg).

${ }^{\mathrm{f}}$ Mean corpuscular hemoglobin concentration (g/dl).

g White blood cell $\left(\times 10^{3} \mathrm{~mm}^{-3}\right)$.

${ }^{\text {h }}$ Segmented leukocyte $(\%)$.

${ }^{\mathrm{i}}$ Lymphocyte (\%).

${ }^{j}$ Monocyte (\%).

${ }^{\mathrm{k}}$ Eosinophilic leukocyte (\%).

${ }^{1}$ Platelets $\left(\times 10^{3} \mathrm{~mm}^{-3}\right)$.

white blood cell count (WBC) and white blood cell differential count. The non-heparinized blood was allowed to coagulate before being centrifuged and the serum separated. The serum was assayed for glucose, creatinine, blood urea nitrogen (BUN), aspartate transaminase (AST), alanine transaminase (ALT), potassium, sodium, chloride, calcium, phosphorus, conjugated billirrubin, total billirrubin, total cholesterol, high density lipoprotein (HDL), triglycerides, total protein, and albumin.

\subsubsection{Tissue analysis}

Immediately after collecting the blood samples, vascular perfusion was performed for tissue fixation using isotonic saline $(250 \mathrm{ml})$ followed by $10 \%$ buffered formalin solution $(250 \mathrm{ml})$. The organs such as liver, lungs, heart, spleen, brain, epididimus, seminal vesicles, adrenals, kidneys, testes and ovaries were removed and weighted immediately on an Ohaus electronic balance for subsequent analysis. Eyes, thymus, intestines, uterus, prostate glands, and muscle with the sciatic nerve were also extracted. Tissues from the control group and the group treated with the high dose Salvia scutellarioides $(2 \mathrm{~g} / \mathrm{kg}$ ) were embedded in paraffin and subjected to hematoxillin-eosin staining. The pathological observations of all tissues were performed on gross and microscopic bases. Histological plates of the preserved tissues were encrypted for analysis by a pathologist (RJ). When lesions were observed in the high dose group, the affected organs were also examined in the low dose group of Salvia scutellarioides $(1 \mathrm{~g} / \mathrm{kg})$.

\subsection{Statistical analysis}

Statistical evaluation was performed using GraphPad Prism Ver. 4.0, for Windows XP. All results are presented as mean \pm S.E.M. Data were analyzed using one-way analysis of variance (ANOVA) and, when appropriate, by a Student-Newman-Keuls test. Results were considered significant at $p<0.05$.

\section{Results}

\subsection{Acute toxicity}

No death was recorded in the 14 days of observation period in the male and female animals given $2 \mathrm{~g} / \mathrm{kg}$ of the water extract of Salvia scutellarioides orally. The animals did not show any changes in the general appearance during the observation period.

\subsection{Subacute toxicity}

\subsubsection{General signs}

No deaths or significant changes in general behavior or other physiological activities were observed at any point in the present study.

\subsubsection{Body weight, blood pressure, food, and water intake}

No changes were observed in SBP or DBP (Table 1). Other parameters like MBP, body weight, food, and water intake did 
Table 3

Blood chemistry values of rats in subacute toxicity of the aqueous extract from Salvia scutellarioides

\begin{tabular}{|c|c|c|c|c|c|c|}
\hline & \multicolumn{3}{|l|}{ Male } & \multicolumn{3}{|l|}{ Female } \\
\hline & \multirow[t]{2}{*}{ Control } & \multicolumn{2}{|c|}{ Salvia scutellarioides $(\mathrm{g} / \mathrm{kg})$} & \multirow[t]{2}{*}{ Control } & \multicolumn{2}{|c|}{ Salvia scutellarioides $(\mathrm{g} / \mathrm{kg})$} \\
\hline & & 1 & 2 & & 1 & 2 \\
\hline $\mathrm{TB}^{\mathrm{a}}$ & $0.17 \pm 0.031$ & $0.19 \pm 0.032$ & $0.22 \pm 0.018$ & $0.23 \pm 0.016$ & $0.19 \pm 0.024$ & $0.20 \pm 0.028$ \\
\hline $\mathrm{CB}^{\mathrm{b}}$ & $0.024 \pm 0.005$ & $0.036 \pm 0.007$ & $0.048 \pm 0.008$ & $0.026 \pm 0.005$ & $0.038 \pm 0.002$ & $0.026 \pm 0.006$ \\
\hline $\mathrm{AST}^{\mathrm{c}}$ & $175.2 \pm 21.51$ & $130.2 \pm 8.35$ & $132 \pm 11.51$ & $162.2 \pm 7.69$ & $128.4 \pm 14.08$ & $200.2 \pm 50$ \\
\hline $\mathrm{ALT}^{\mathrm{d}}$ & $48.2 \pm 4.62$ & $46.2 \pm 2.33$ & $37.6 \pm 1.03$ & $36.0 \pm 5.51$ & $31.0 \pm 2.03$ & $34.4 \pm 5.42$ \\
\hline Total proteins $(\mathrm{g} / \mathrm{dl})$ & $7.3 \pm 0.25$ & $7.74 \pm 0.26$ & $7.84 \pm 0.17$ & $7.52 \pm 0.15$ & $7.68 \pm 0.07$ & $7.84 \pm 0.09$ \\
\hline Albumin $(\mathrm{g} / \mathrm{dl})$ & $2.32 \pm 0.15$ & $2.65 \pm 0.05$ & $2.83 \pm 0.22$ & $2.74 \pm 0.09$ & $2.93 \pm 0.08$ & $3.0 \pm 0.2$ \\
\hline $\mathrm{BUN}^{\mathrm{e}}$ & $20.2 \pm 1.38$ & $21.1 \pm 1.12$ & $20.6 \pm 1.03$ & $19.9 \pm 1.78$ & $17.0 \pm 1.32$ & $21.24 \pm 1.0$ \\
\hline Creatinine (mg/dl) & $0.92 \pm 0.04$ & $0.91 \pm 0.02$ & $0.89 \pm 0.02$ & $0.87 \pm 0.06$ & $0.94 \pm 0.02$ & $0.98 \pm 0.02$ \\
\hline $\mathrm{HDL}^{\mathrm{f}}$ & $34.0 \pm 2.07$ & $37.6 \pm 2.87$ & $40.2 \pm 2.69$ & $39.0 \pm 1.48$ & $40.8 \pm 1.24$ & $37.0 \pm 1.95$ \\
\hline Colesterol (mg/dl) & $52.8 \pm 2.87$ & $51.8 \pm 4.71$ & $55.8 \pm 3.99$ & $56.6 \pm 7.56$ & $57.6 \pm 2.29$ & $48.2 \pm 3.65$ \\
\hline $\mathrm{TG}^{\mathrm{g}}$ & $40.8 \pm 13.7$ & $35.2 \pm 8$ & $23.2 \pm 0.66$ & $47.4 \pm 10.21$ & $34.2 \pm 3.46$ & $33.4 \pm 6.81$ \\
\hline Potassium (mequiv./L) & $5.84 \pm 0.34$ & $5.24 \pm 0.15$ & $6.0 \pm 0.13$ & $5.78 \pm 0.35$ & $5.98 \pm 0.14$ & $6.3 \pm 0.3$ \\
\hline Sodium (mequiv./l) & $155.4 \pm 1.69$ & $155.4 \pm 3.06$ & $160 \pm 2.03$ & $154.6 \pm 1.69$ & $151.2 \pm 1.16$ & $156.2 \pm 1.02$ \\
\hline Chloride (mequiv./l) & $93.4 \pm 3.51$ & $99.2 \pm 1.02$ & $97.6 \pm 1.17$ & $101 \pm 1.41$ & $95.6 \pm 2.22$ & $98.4 \pm 0.75$ \\
\hline Calcium (mg/dl) & $9.7 \pm 0.21$ & $10.17 \pm 0.14$ & $9.93 \pm 0.22$ & $9.94 \pm 0.29$ & $10.21 \pm 0.27$ & $10.61 \pm 0.47$ \\
\hline Phosphorus (mg/dl) & $8.34 \pm 0.62$ & $7.04 \pm 0.56$ & $8.78 \pm 0.4$ & $7.74 \pm 0.24$ & $8.06 \pm 0.60$ & $8.58 \pm 0.88$ \\
\hline $\mathrm{PT}^{\mathrm{h}}$ & $9.98 \pm 0.72$ & $14.23 \pm 4.2$ & $11.23 \pm 1.3$ & $11.7 \pm 0.87$ & $10.9 \pm 1.91$ & $16.9 \pm 3.35$ \\
\hline PTT $^{\mathrm{i}}$ & $23.5 \pm 2.71$ & $36.4 \pm 9.02$ & $23.2 \pm 4.62$ & $26.2 \pm 2.53$ & $27.3 \pm 4.76$ & $41.55 \pm 8.36$ \\
\hline Glucose (mg/dl) & $231.6 \pm 21.81$ & $216.8 \pm 10.8$ & $174.6 \pm 23$ & $239.6 \pm 24.8$ & $243.4 \pm 24.7$ & $298.4 \pm 11.8$ \\
\hline
\end{tabular}

Data are expressed as mean \pm S.E.M., $n=5$. No statistical difference between control and Salvia scutellarioides $(P>0.05)$.

a Total billirrubin $(\mathrm{mg} / \mathrm{dl})$.

b Direct billirrubin $(\mathrm{mg} / \mathrm{dl})$.

c Aspartate transaminase ((U/l).

d Alanine transaminase $((\mathrm{U} / \mathrm{l})$.

e Blood urea nitrogen $(\mathrm{mg} / \mathrm{dl})$.

${ }^{\mathrm{f}}$ High density lipoproteins $(\mathrm{mg} / \mathrm{dl})$.

g Triglycerides (mg/dl).

${ }^{\text {h }}$ Prothrombin time.

i Thromboplastin partial time.

Table 4

Organ weights of rats in subacute toxicity of the aqueous extract from Salvia scutellarioides

\begin{tabular}{|c|c|c|c|c|c|c|}
\hline & \multicolumn{3}{|l|}{ Male } & \multicolumn{3}{|l|}{ Female } \\
\hline & \multirow[t]{2}{*}{ Control } & \multicolumn{2}{|c|}{ Salvia scutellarioides $(\mathrm{g} / \mathrm{kg})$} & \multirow[t]{2}{*}{ Control } & \multicolumn{2}{|c|}{ Salvia scutellarioides $(\mathrm{g} / \mathrm{kg})$} \\
\hline & & 1 & 2 & & 1 & 2 \\
\hline Brain & $1.61 \pm 0.11$ & $1.57 \pm 0.12$ & $1.47 \pm 0.07$ & $1.55 \pm 0.12$ & $1.66 \pm 0.09$ & $1.31 \pm 0.08$ \\
\hline Heart & $0.89 \pm 0.2$ & $0.92 \pm 0.02$ & $0.98 \pm 0.04$ & $0.81 \pm 0.03$ & $0.72 \pm 0.02$ & $0.76 \pm 0.03$ \\
\hline Lungs & $2.95 \pm 0.28$ & $2.49 \pm 0.13$ & $2.71 \pm 0.21$ & $2.7 \pm 0.17$ & $2.69 \pm 0.12$ & $2.35 \pm 0.25$ \\
\hline Spleen & $0.66 \pm 0.05$ & $0.67 \pm 0.05$ & $0.68 \pm 0.04$ & $0.64 \pm 0.03$ & $0.65 \pm 0.04$ & $0.59 \pm 0.03$ \\
\hline Kidneys & $2.28 \pm 0.12$ & $2.26 \pm 0.14$ & $2.33 \pm 0.19$ & $1.81 \pm 0.08$ & $1.77 \pm 0.1$ & $1.58 \pm 0.08$ \\
\hline Stomach & $2.05 \pm 0.10$ & $2.32 \pm 0.11$ & $2.24 \pm 0.13$ & $1.97 \pm 0.08$ & $1.76 \pm 0.05$ & $1.71 \pm 0.12$ \\
\hline Pancreas & $1.3 \pm 0.10$ & $1.43 \pm 0.17$ & $1.53 \pm 0.15$ & $1.22 \pm 0.08$ & $1.6 \pm 0.08$ & $1.4 \pm 0.17$ \\
\hline Testis & $3.13 \pm 0.05$ & $3.23 \pm 0.06$ & $3.31 \pm 0.09$ & - & - & - \\
\hline $\mathrm{SV}$ and $\mathrm{Epi}^{\mathrm{a}}$ & $2.78 \pm 0.39$ & $2.49 \pm 0.32$ & $2.4 \pm 0.30$ & - & - & - \\
\hline Ovaries & - & - & - & $0.17 \pm 0.01$ & $0.18 \pm 0.01$ & $0.17 \pm 0.01$ \\
\hline
\end{tabular}

Data are expressed as mean \pm S.E.M., $n=5$. No statistical difference between control and Salvia scutellarioides $(P>0.05)$.

${ }^{a} \mathrm{SV}$ and Epi: seminal vesicles and epididimus. 
not show any significant differences in either the control or treated group of both sexes (data not shown).

\subsubsection{Urinalysis}

The urinalysis in the control and treated groups of both male and female rats were negative for glucose, ketonic bodies, casts, red blood cells, and albumin.

\subsubsection{Hematological and plasma biochemical data}

The hematological analysis (Table 2), showed no significant changes of $\mathrm{RBC}, \mathrm{Hb}, \mathrm{Ht}, \mathrm{WBC}$, and platelets in the male and female treatment group compared to the control group. The leukocyte differential count showed no difference between groups; some bands (up to $2 \%$ ) were occasionally found in some rats of the control and treatment groups.

The biochemical analysis (Table 3), showed no significant differences in any of the parameters examined in either the control or treated group of the male and female rats.

\subsubsection{Tissue analysis}

There were no significant differences between the control and treated groups in the organ weights of male and female rats (Table 4). Pathological examinations of the tissues on a gross basis indicated that there were no detectable abnormalities. No alterations were seen in the microscopic examination of the internal organs; the cellular appearances were unremarkable in both groups and sexes.

\section{Discussion and conclusion}

The acute toxicity study does not show any toxic symptoms, changes in behavior or mortality at $2 \mathrm{~g} / \mathrm{kg}$ doses. The subacute toxicity guideline applied (OECD, 2001a) considers unnecessary a full study with three dose levels when at least $1 \mathrm{~g} / \mathrm{kg}$ day does not show toxicity effects, as was observed in the acute toxicity experiment. The high dose Salvia scutellarioides ( $2 \mathrm{~g} / \mathrm{kg}$ day) in the subacute study was applied because human exposure indicates the use of a high dose level in accord with the subacute guideline (OECD, 2001a). A lower dose of $1 \mathrm{~g} / \mathrm{kg}$ day was used to determine dose related toxic effects. In a subacute toxicity study, it appeared that the water extract of Salvia scutellarioides at the doses used did not produce any marked changes in both male and female rats, as evidenced by the absence of toxic symptoms, no changes in water/food ingestion, or weight gain.

All animals survived until the scheduled euthanasia and no gross pathological alteration was found in the internal organs. Organ weight revealed that Salvia scutellarioides, at the doses used, did not produce organ swelling, atrophy or hypertrophy. Moreover, the microscopic evaluation did not find any abnormalities in the $2 \mathrm{~g} / \mathrm{kg}$ Salvia scutellarioides group compared to the control group. Microscopic evaluation in the $1 \mathrm{~g} / \mathrm{kg}$ group was not performed in accordance with the subacute guideline (OECD, 2001a), that considers unnecessary the microscopic examination of organs in the low dose group when no histopathological abnormalities are found in the high dose group. The comparable biochemical results in the control group and Salvia scutellarioides treated groups were consistent with the morphological analysis. Our research group recently described the association between the diuretic effect of Salvia scutellarioides with an increase in the urinary potassium excretion (Ramirez et al., 2006a). However no serum potassium abnormalities were found in the subacute toxicity study, a finding probably related to proximal tubular hypertrophy; a common diuretic tolerance mechanism taking place after chronic dosing and not with single dose administration as was the case of the diuretic study (Kim, 2004). Nevertheless, there is a possibility for some herbaldrug interactions, including an exacerbation of hypokalemia in patients taking concomitantly Salvia scutellarioides with diuretics, or an increase in digoxin related arrhythmias. These type of herbal-drug interactions has been already described with other medicinal plants (Izzo et al., 2005). Systolic and diastolic blood pressures were not altered by the administration of Salvia scutellarioides. However, Salvia scutellarioides diminished diastolic blood pressure in L-NAME hypertensive rats (Ramirez et al., 2006b), and decreased the contractile response of the aorta to phenylephrine (data not published). The failure of the aqueous extract of Salvia scutellarioides to lower the blood pressure in this study could be explained by renal and autonomic homeostatic mechanisms in normotensive animals that are capable of compensating a pharmacological reduction in blood pressure (Pinto et al., 1998). These mechanisms include an increase in sodium reabsorption in the proximal tubule (Magyar et al., 2001), a decrease in the production of nitric oxide (Pechanova et al., 2004), and an increase in production of the neurohumoral mediators adrenaline (Huang et al., 2003) and angiotensin II (Nabah et al., 2005). As opposed to normotensive animals, some of these homeostatic mechanisms are absent in most animal models of hypertension, allowing the reduction of blood pressure by a specific pharmacological manipulation.

In summary the aqueous extract of Salvia scutellarioides was found to be nontoxic when oral acute and subacute toxicities in rats were performed. Chronic toxicity, mutagenicity and carcinogenicity studies are necessary to further support the safe use of this plant. The possible interaction of Salvia scutellarioides with drugs like digoxin and diuretics should be considered in future studies.

\section{Acknowledgements}

This project was possible thanks to the financial support of COLCIENCIAS (Colombian Institute for the Development of Science and Technology) and Universidad del Valle co-joint research grant 11060413079 . We would also like to thank Professor Luis Eduardo Bravo for the revision of the paper.

\section{References}

Colmenares, A.J., Ramírez, A.B., 2001. Treinta plantas medicinales del Valle del Cauca. Feriva, Cali, Colombia, pp. 49-50.

Garcia, H., 1992. Flora medicinal de Colombia. Tercer Mundo Editores, Bogota, pp. 33-34.

Gonzalez, A.G., Grillo, T.A., Luis, J.G., Vazquez, J.T., Rodriguez, M.L., Ravelo, J.L., Calle, J., Rivera, A., 1990. Sesquiterpene lactones from Salvia palaefolia. Phytochemistry 29, 3581-3585. 
Huang, F., Villafana, S., Hong, E., 2003. Role of central and sympathetic nervous systems in pressor effect of L-NAME. Journal of Cardiovascular Pharmacology 41, 68-72.

Izzo, A.A., Di, C.G., Borrelli, F., Ernst, E., 2005. Cardiovascular pharmacotherapy and herbal medicines: the risk of drug interaction. International Journal of Cardiology 98, 1-14.

Kim, G.H., 2004. Long-term adaptation of renal ion transporters to chronic diuretic treatment. American Journal of Nephrology 24, 595-605.

Magyar, C.E., Zhang, Y., Holstein-Rathlou, N.H., McDonough, A.A., 2001. Downstream shift in sodium pump activity along the nephron during acute hypertension. Journal of the American Society of Nephrology 12, 2231-2240.

Nabah, Y.N., Mateo, T., Cerda-Nicolas, M., Alvarez, A., Martinez, M., Issekutz, A.C., Sanz, M.J., 2005. L-NAME Induces direct arteriolar leukocyte adhesion, which is mainly mediated by angiotensin-II. Microcirculation 12, 443-453.

Pechanova, O., Dobesova, Z., Cejka, J., Kunes, J., Zicha, J., 2004. Vasoactive systems in L-NAME hypertension: the role of inducible nitric oxide synthase. Journal of Hypertension 22, 167-173.
Piñeros, C.J., Garcia, H.B., Iregui, A.B., Prias, E.L., Perdomo, C., 1991. Plantas Medicinales: Compendio de Farmacología Vegetal. Fedicor, Bogotá, pp. 42-83.

Pinto, Y.M., Paul, M., Ganten, D., 1998. Lessons from rat models of hypertension: from goldblatt to genetic engineering. Cardiovascular Research 39, 77-88.

Ramirez, J.H., Palacios, M., Gutiérrez, J.O., 2006a. Diuretic effect of an infusion of the herbal plant, Salvia scutellarioides, in rats. Biomédica 26, 145149.

Ramirez, J.H., Palacios, M., Gutierrez, J.O., 2006b. Evaluation of the antihypertensive effect of Salvia scutellarioides in a rat model of hypertension. Colombia Medica 37, 53-60.

The Organization of Economic Co-operation Development (OECD), 2001a. The OECD Guideline for Testing of Chemical: 407 Repeated Dose Oral ToxicityRodent: 28-Day or 14-Day Study. OECD, Paris, pp. 1-7.

The Organization of Economic Co-operation Development (OECD), 2001b. The OECD Guideline for Testing of Chemical: 420 Acute Oral Toxicity. OECD, Paris, pp. 1-14. 